\title{
Complications and loss of free flaps after reconstructions for oral cancer
}

\author{
E. Marttila ${ }^{\text {a, }}$, H. Thorén ${ }^{\text {b,c }}$, J. Törnwall ${ }^{\text {a }}$, A. Viitikko ${ }^{\text {a }}$, T. Wilkman ${ }^{\text {a }}$ \\ a Department of Oral and Maxillofacial Diseases, Helsinki University Hospital, PO Box 220, FI-00029 Helsinki, Finland \\ ${ }^{\mathrm{b}}$ Department of Oral and Maxillofacial Surgery, Institute of Dentistry, University of Turku, Lemminkäisenkatu 2, FI-20520 Turku, Finland \\ ${ }^{c}$ Department of Oral and Maxillofacial Diseases, Turku University Hospital, Lemminkäisenkatu 2, FI-20520 Turku, Finland
}

Received 19 March 2018; accepted 10 September 2018

Available online 15 October 2018

\begin{abstract}
The aim of this retrospective study was to analyse the incidence of complications and loss of flaps after primary reconstructions for oral cancer in 191 patients at our hospital over the five years 2005-2010. The patients' clinical and personal details, characteristics of the tumours, types of microvascular flap, complications, and outcomes were recorded. The soft tissue flaps used most often were the fasciocutaneous radial forearm free flap (RFFF) $(n=86,45 \%)$ and the anterolateral thigh free flap (ALTFF) $(n=48,25 \%)$ while the most commonly used osseous flap was the deep circumflex iliac artery flap (DCIA) $(n=25,13 \%)$. There were postoperative complications that required intervention in a quarter of the patients, most often in the age group $41-50$ years $(\mathrm{p}=0.018)$. Older age was not associated with the development of complications. The overall survival of all free flaps was 181/191 (95\%), and the only significant individual predictor of loss of a flap was reconstruction with a DCIA ( $p=0.016)$, five of the 25 of which were lost. We conclude therefore that DCIA free flaps are associated with an increased risk of failure; the method of osseous reconstruction for maxillofacial reconstruction should be selected carefully; and carefully chosen older patients do not seem to be at increased risk of morbidity.
\end{abstract}

(C) 2018 The British Association of Oral and Maxillofacial Surgeons. Published by Elsevier Ltd. All rights reserved.

Keywords: Free flap reconstruction; complication; microsurgery; deep circumflex iliac artery flap; outcome; elderly

\section{Introduction}

Malignant tumours of the oral cavity often require extensive resections that leave large defects in the soft and hard tissue, which may lead to loss of function such as swallowing, speech, and mastication, and may also compromise breathing.

Microvascular free flaps are often necessary in the reconstruction of these extensive defects to maintain function and facial symmetry. ${ }^{1,2}$ Reconstructions with such flaps are long

\footnotetext{
* Corresponding author. Fax: +358947188505.

E-mail address: emilia.marttila@helsinki.fi (E. Marttila).
}

and complex procedures that require many resources and much preoperative planning. The most commonly used free soft tissue flaps are the radial forearm free flap (RFFF) and the anterolateral thigh free flap (ALTFF), whereas the fibular flap is the most used osseous free flap, followed by the deep circumflex iliac artery flap (DCIA), and the scapular free flap. Survival rates range between $85 \%-100 \%{ }^{3-8}$ However, despite good survival rates, overall free flap morbidity is reported to be as high as $28 \%-50 \%$. $3,4,9-11$

Common failures of these flaps include thrombosis of the arterial or venous anastomosis, infection, development of a fistula, wound dehiscence, haematoma, and haemorrhage. ${ }^{6,12,13}$ Vascular thrombosis requires immediate 
re-exploration to salvage the flap and prevent necrosis. ${ }^{13}$ Such complications prolong hospital stay, increase morbidity and mortality, and decrease quality of life while increasing the overall cost of treatment. ${ }^{10}$ It is therefore important to be able to identify the factors that predict failure or complications, and minimise their risks. Secondary reconstructions are less successful that primary reconstructions. ${ }^{14,15}$

The aim of the present study was to identify the types and rate of complications after primary reconstruction with microvascular free flaps after resections of oral cancer during a five-year period at the Oral and Maxillofacial department of the University Hospital, Helsinki, Finland.

\section{Patients and methods}

We designed and implemented a retrospective cohort study in which we included the casenotes of all patients who had had primary reconstruction with a microvascular free flap after resection of oral cancer at our hospital between January 2005 and December 2010. Patients who had secondary reconstructions were excluded. The internal review board of the Division of Musculoskeletal Surgery, Helsinki University Hospital approved the study.

For each patient the following data were recorded: age, sex, histopathological type and anatomical site of the tumour, postoperative staging of squamous cell carcinoma (SCC), type of microvascular flap used, postoperative complications that required operation, and time between reconstruction and surgical treatment of the complication. The anatomical sites of the tumours were classified as: tongue; floor of the mouth; soft palate and oropharynx; buccal mucosa; mandibular gingiva; maxillary gingiva; mucosa of the hard palate; mandible; and maxilla. Complications that required intervention were grouped/patient as: vascular compromise; infection, or wound dehiscence, or both; haemorrhage or haematoma; partial necrosis; pharyngeal swelling; and failure of osteosynthesis. Based on the duration of time between reconstruction and treatment of the complication, complications were classified as early (fewer than 15 days) or late (15 days or more). Early complications were further classified as follows: $<24$ hours; $24-72$ hours; 73 hours -7 days; and 8-14 days.

\section{Statistical analysis}

Data were analysed by using GraphPad Prism version 5.00 (GraphPad Inc). The two-tailed Mann Whitney test and oneway ANOVA with Bonferroni post hoc correction were used to assess the significance of differences between groups, and the chi squared test to assess the significance of differences between failure and different variables. Probabilities of less than 0.05 were accepted as significant. The primary end points were complication requiring intervention, vascular compromise, and loss of the flap.
Table 1

Personal and clinical details of patients $(n=191)$.

\begin{tabular}{ll}
\hline & No. $(\%)$ of patients \\
\hline Sex: & \\
Male & $112(59)$ \\
Female & $79(41)$ \\
Age groups (years) & \\
$29-40$ & $7(4)$ \\
$41-50$ & $15(8)$ \\
$51-60$ & $51(27)$ \\
$61-70$ & $63(33)$ \\
$71-80$ & $40(21)$ \\
$81-91$ & $15(8)$ \\
Histopathological type of tumour: & \\
Squamous cell carcinoma & $169(89)$ \\
Small salivary gland carcinoma & $16(8)$ \\
Bony tumour: & $6(3)$ \\
Sarcoma & 3 \\
Metastatic tumour & 2 \\
Primary intraosseus carcinoma & 1 \\
Stage of squamous cell carcinoma: & \\
I & 55 \\
II & 24 \\
III & 17 \\
IVA & 68 \\
IVB & 5 \\
Anatomical site of tumour: & \\
Tongue & $56(29)$ \\
Gingiva/mandible & $40(21)$ \\
Floor of the mouth & $36(19)$ \\
Gingiva/maxilla & $17(9)$ \\
Buccal mucosa & $17(9)$ \\
Soft palate/oropharynx & $14(7)$ \\
Hard palate mucosa & $5(3)$ \\
Mandible & $3(2)$ \\
Maxilla & $3(2)$ \\
\hline &
\end{tabular}

\section{Results}

A total of 300 patients treated surgically for head and neck malignancy between 2005 and 2010 were identified from the database of the Department of Oral and Maxillofacial Diseases. Of these, 197 had been treated by primary microvascular free flap reconstruction. Six patients had incomplete data, leaving 191 patients for the final analysis.

Table 1 shows clinical and personal details of the patients. Most of the patients were male and the mean (range) age was 64 (29-91) years. A total of 176/191 required neck dissection (93\%). Table 2 shows the most commonly used flaps.

Postoperative complications that required surgical intervention are shown in Table 3. Routine elective tracheostomy is not used in our clinic. Patients are monitored closely postoperatively and tracheostomy done only if pharyngeal swelling develops. Two patients showed signs of pharyngeal swelling that required tracheostomy, and for both the swelling was diagnosed within 24 to 72 hours of operation.

Table 4 shows the association between complications and patients' variables.

Eleven flaps were lost, the rate of flap loss/patient and loss/flap being $5.8 \%$ and $5.5 \%$, respectively (Table 5). All 
Table 2

Types of flaps used for reconstruction. The total number of free flaps was 200 as in nine patients two free flaps were used simultaneously.

\begin{tabular}{ll}
\hline Type of free flap & No. $(\%)$ \\
\hline Radial forearm (RF) & $86(45)$ \\
Anterolateral thigh (ALT) & $48(25)$ \\
Deep circumflex iliac artery (DCIA) & $25(13)$ \\
Scapula/parascapula & $7(4)$ \\
Other single flaps: & $18(9)$ \\
Serratus & 4 \\
Rectus abdominis & 3 \\
Latissimus dorsi & 3 \\
Fibular & 3 \\
Lateral arm & 3 \\
Temporoparietal & 1 \\
Tensor fascia lata & 1 \\
Two simultaneous flaps: & $7(4)$ \\
ALT + DCIA & 3 \\
ALT + fibula & 2 \\
RA + DCIA & 2 \\
\hline
\end{tabular}

four venous thromboses that occurred within 24 hours of operation were saved, whereas the three that occurred later were lost. The one arterial thrombosis that occurred within 24 hours was lost. There was no significant association between loss of a flap and sex, age, histopathological type of tumour, stage of SCC, or anatomical site of tumour. Osseous flaps were significantly more likely to fail than soft tissue flaps $(p=0.016)$. The only significant individual predictor of flap loss was reconstruction with a DCIA flap $(p=0.016)$ (Table 4). Loss of the flap was treated successfully in all 11 patients: seven flaps were replaced with another microvascular free flap, and four with a pectoralis major myocutaneous flap.

\section{Discussion}

Free flaps are considered to be the main technique for reconstruction of large defects in the soft and hard tissue after resection of tumours in the head and neck. Despite free flaps having good overall survival, complications are fairly common and are reported to be as high as $28 \%-50 \% .^{3,4,9-11} \mathrm{We}$ found both early and late postoperative complications that required intervention in a quarter of the patients. The overall survival of all free flaps was $181 / 191(95 \%)$. This is consistent with results reported from other centres, where the survival rate of free flaps has been reported to range between $85 \%-100 \% .^{3-6,8}$ It is natural that there should be a learning curve, with an increased number of complications and failures in the beginning. However, our reconstructions were all done by the same surgeons between 2005 and 2010 and so were not influenced by these early difficulties.

The DCIA was the flap most often used in our series. As this was a retrospective study the choice of free flap used was based on the subjective preference of the surgeon. Microvascular reconstructions have been done at our clinic since the early 1990s, the DCIA was the first osseous free flap to be introduced, and was the most popular osseus flap at the beginning of this series. Later, the use of the fibular flap increased.

Our only significant predictor of loss of a flap was the use of the DCIA for reconstruction. Five DCIA flaps out of a total of 11 were lost. Wilkman et al also found that the DCIA was associated with a significantly greater loss than other osseous free flaps. ${ }^{16}$ In a meta-analysis by Markiewicz et al the DCIA flap was associated with a seven-fold increase in failure compared with the RFFF in mandibular reconstruction..$^{5}$ The fibular free flap has been shown to be the most stable, and has the least bony resorption compared with scapular or iliac crest flaps. ${ }^{17}$ The DCIA provides a good stock of bone and soft tissue, but the skin island is often scarce and the pedicle of limited length, and it might require additional vein grafting, which may lead to more complications. Among older patients the presence of atherosclerosis may prevent the use of the fibular flap, so evaluation of the vascular status is essential to prevent donor site morbidity.

Table 3

Types of complication that required intervention $(n=48)$ and time of occurrence of complications in the 191 patients. Early complications occurred within 15 days of operation, and late complications after 15 days. Early complications were further classified as (I) $<24$ hours, (II) 24 to 72 hours, (III) 73 hours to 7 days, and (IV) 8 to 14 days.

\begin{tabular}{|c|c|c|c|c|c|c|}
\hline \multirow[t]{2}{*}{ Type of complication } & \multirow[t]{2}{*}{ No. $(\%)$ of patients } & \multicolumn{4}{|c|}{ No. of early complications } & \multirow[t]{2}{*}{ Late complications } \\
\hline & & I & II & III & IV & \\
\hline Infection and/or wound dehiscence & $15(8)$ & - & - & 3 & 5 & 7 \\
\hline Vascular compromise: & $11(6)$ & 5 & 1 & 2 & 3 & - \\
\hline Venous thrombosis & 7 & - & - & - & - & - \\
\hline Arterial thrombosis & 3 & - & - & - & - & - \\
\hline Venous + arterial thrombosis & 1 & - & - & - & - & - \\
\hline Partial necrosis & $9(5)$ & - & - & 2 & 3 & 4 \\
\hline Haemorrhage or haematoma: & $9(5)$ & 3 & 3 & 2 & - & 1 \\
\hline Haemorrhage & 5 & - & - & - & - & - \\
\hline Haematoma & 4 & - & - & - & - & - \\
\hline Pharyngeal swelling & $2(1)$ & - & 2 & - & - & - \\
\hline Failure of osteosynthesis & $2(1)$ & - & - & - & - & 2 \\
\hline Total & $48(25)$ & 8 & 6 & 9 & 11 & 14 \\
\hline
\end{tabular}


Table 4

The associations between the patients' variables and complications that required intervention, vascular compromise, and loss of the flap.

\begin{tabular}{|c|c|c|c|c|}
\hline & Total No. & No. $(\%)$ complications & No. with vascular compromise & No. of flaps lost \\
\hline \multicolumn{5}{|l|}{ Sex: } \\
\hline Female & 79 & 33 & 5 & 7 \\
\hline Male & 112 & $15(19)$ & $6(5)$ & $4(5)$ \\
\hline \multicolumn{5}{|l|}{ Age group (years): } \\
\hline $29-40$ & 7 & 0 & 0 & 0 \\
\hline $41-50$ & 15 & $8^{*}$ & 2 & 2 \\
\hline $51-60$ & 52 & 17 & 5 & 6 \\
\hline $61-70$ & 63 & 14 & 4 & 3 \\
\hline $71-80$ & 39 & 5 & 0 & 0 \\
\hline $81-91$ & 15 & 4 & 0 & 0 \\
\hline Squamous cell carcinoma & 169 & $41(24)$ & $10(6)$ & $9(5)$ \\
\hline Small salivary gland carcinoma & 16 & 4 & 1 & 2 \\
\hline Bony tumour: & 6 & 4 & 0 & 0 \\
\hline Sarcoma & 3 & & & \\
\hline Metastatic tumour of jaw & 2 & & & \\
\hline Primary intraosseous carcinoma & 1 & & & \\
\hline \multicolumn{5}{|l|}{ Stage of squamous cell carcinoma: } \\
\hline I & 55 & 11 & 2 & 2 \\
\hline II & 24 & 3 & 1 & 1 \\
\hline III & 17 & 5 & 1 & 1 \\
\hline IVA/IVB & 73 & 21 & 6 & 5 \\
\hline \multicolumn{5}{|l|}{ Anatomical site of tumour: } \\
\hline Tongue & 56 & 9 & 1 & 0 \\
\hline Gingiva/mandible & 40 & 13 & 4 & 4 \\
\hline Floor of the mouth & 36 & 9 & 3 & 3 \\
\hline Gingiva/maxilla & 17 & 7 & 2 & 2 \\
\hline Buccal mucosa & 17 & 3 & 0 & 1 \\
\hline Soft palate/oropharynx & 14 & 2 & 0 & 0 \\
\hline Hard palate mucosa & 5 & 1 & 1 & 1 \\
\hline Mandible & 3 & 2 & 0 & 0 \\
\hline Maxilla & 3 & 2 & 0 & 0 \\
\hline \multicolumn{5}{|l|}{ Type of flap: } \\
\hline Radial forearm fasciocutaneous & 86 & 19 & 3 & 3 \\
\hline Anterolateral thigh & 48 & 10 & 1 & 1 \\
\hline Deep circumflex iliac artery & 25 & 9 & 3 & $5^{* *}$ \\
\hline Scapula/parascapula & 7 & 3 & 1 & 0 \\
\hline Other single flaps & 18 & 4 & 3 & 2 \\
\hline Two simultaneous flaps & 7 & 3 & 0 & 0 \\
\hline
\end{tabular}

$* p=0.018$.

** $\mathrm{p}=0.016$.

We did not find that older age increased the risk of failure of the flap or complications, which is important as most patients with oral cancer are over the age of 60 and the age of patients is slowly increasing. ${ }^{7}$ Several studies have confirmed our findings that greater age is not associated with increased risk of failure of the flap and complications. ${ }^{3,18-21}$

We found that complications were most common in the age group 41-50 years. Because older patients tend to have more coexisting conditions, the selection for those to have curative ablative surgery is made with more consideration than that of younger patients, who are treated more aggressively despite their general condition. This may bias the results. However, according to our results if preoperative risk factors are taken into consideration even extensive surgery including reconstruction with a free flap may be safe in older patients.

The lowest failure and complication rates in our series were in the ALT free flap group, with a failure rate of $1 / 48$ $(2 \%)$. ALT flaps have proved to be reliable, with low morbid- ity at both donor and recipient sites. ${ }^{22}$ The RFFF was the flap used most often, in 86/191 cases (45\%). Like other centres, our failure rate $(3.5 \%)$ was low (23). ${ }^{23}$ The RFFF is commonly used in the reconstruction of cancers of the head and neck, and its advantage in oral reconstruction is that it is thin and is therefore more suitable for mucosal replacement than other bulkier flaps. It also offers a good, long pedicle and is usable in both intraoral and extraoral defects.

The most common complications were infection or wound dehiscence, or both, in $15(8 \%)$, vascular compromise in $11(6 \%)$, partial necrosis in nine $(5 \%)$, and haemorrhage or haematoma in nine $(5 \%)$ of the patients. Venous thrombosis was over twice as common as arterial thrombosis. Of the 48 patients with free flap complications, 34 had complications during the first 14 days postoperatively, and 14 had late complications. Those that developed within the first 24 hours were vascular compromise and haematoma. Arterial thrombosis occurs more typically within the first postoperative days 
Table 5

A total of 11 flaps were lost. Specifics of flaps used, reason for loss, and time of loss.

\begin{tabular}{lll}
\hline $\begin{array}{l}\text { Type of } \\
\text { free flap }\end{array}$ & $\begin{array}{l}\text { Postoperative days } \\
\text { at loss of flap }\end{array}$ & $\begin{array}{l}\text { Reason for loss of } \\
\text { flap }\end{array}$ \\
\hline DCIA & 2 & Arterial thrombosis \\
DCIA & 9 & Venous thrombosis \\
DCIA & 12 & Venous thrombosis \\
DCIA & 11 & Wound dehiscence \\
DCIA & 810 & Infection and failure of osteosynthesis \\
RF & $<1$ & Arterial thrombosis \\
RF & 4 & Arterial and venous thrombosis \\
RF & 5 & Venous thrombosis \\
TFL & 130 & Infection \\
ALT & 390 & Infection \\
\hline
\end{tabular}

$\mathrm{DCIA}=$ deep circumflex iliac artery $\mathrm{RF}=$ radial forearm; $\mathrm{TFL}=$ tensor fascia lata; and ALT $=$ anterolateral thigh.

and is less likely to result in salvage of the flap than venous thrombosis. ${ }^{13}$ Our three arterial thromboses all developed within the first four days of operation and they all led to loss of the flap. The one arterial thrombosis that occurred within 24 hours was also lost.

Common causes of arterial thrombosis are bleeding, extrinsic compression, and kinking of the vessel. ${ }^{13}$ All four of the venous thromboses that developed within 24 hours of operation were saved, whereas the three later venous thromboses were lost. Overall vascular compromise usually occurs within two days of operation. Early postoperative monitoring for the detection of flap-associated complications is important, but later frequent monitoring should not be forgotten.

In conclusion, DCIA free flaps are associated with a significantly increased risk of failure, which may be the result of poor selection of either patient or flap, the inexperience of the surgeon, or complications during the operation. Osseous free flaps should be chosen carefully for reconstruction after resection of a tumour. Carefully selected older patients are not at increased risk of complications or failure of a free flap. Frequent postoperative monitoring for the detection of complications is important, and may prevent loss of the flap.

\section{Ethics statement/confirmation of patients' permission}

The internal review board of the Division of Musculoskeletal Surgery, Helsinki University Hospital, Finland approved the study. Patients' permission was obtained.

\section{Conflict of interest}

We have no conflicts of interest.

\section{Funding}

This work was supported by The Emil Aaltonen Foundation (grant number 160164) and The Finnish Medical Foundation (grant for EM).

\section{References}

1. Borggreven PA, Aaronson NK, Verdonck-de Leeuw IM, et al. Quality of life after surgical treatment for oral and oropharyngeal cancer: a prospective longitudinal assessment of patients reconstructed by a microvascular flap. Oral Oncol 2007;43:1034-42.

2. McCarthy CM, Cordeiro PG. Microvascular reconstruction of oncologic defects of the midface. Plast Reconstr Surg 2010;126:1947-59.

3. Bozikov K, Arnez ZM. Factors predicting free flap complications in head and neck reconstruction. J Plast Reconstr Aesthet Surg 2006;59:737-42.

4. Lodders JN, Parmar S, Stienen NL, et al. Incidence and types of complications after ablative oral cancer surgery with primary microvascular free flap reconstruction. Med Oral Patol Oral Cir Bucal 2015;20:e744-50.

5. Markiewicz MR, Bell RB, Bui TG, et al. Survival of microvascular free flaps in mandibular reconstruction: A systematic review and metaanalysis. Microsurgery 2015;35:576-87.

6. Zhang C, Sun J, Zhu H, et al. Microsurgical free flap reconstructions of the head and neck region: Shanghai experience of 34 years and 4640 flaps. Int J Oral Maxillofac Surg 2015;44:675-84.

7. Husso A, Mäkitie AA, Vuola J, et al. Evolution of head and neck microvascular reconstructive strategy at an academic centre: an 18-year review. J Reconstr Microsurg 2016;32:294-300.

8. Ishimaru M, Ono S, Suzuki S, et al. Risk factors for free flap failure in 2,846 patients with head and neck cancer: a national database study in Japan. J Oral Maxillofac Surg 2016;74:1265-70.

9. Clark JR, McCluskey SA, Hall F, et al. Predictors of morbidity following free flap reconstruction for cancer of the head and neck. Head Neck 2007;29:1090-101.

10. Hand WR, McSwain JR, McEvoy M, et al. Characteristics and intraoperative treatments associated with head and neck free tissue transfer complications and failures. Otolaryngol Head Neck Surg 2015;152:480-7.

11. Kim H, Jeong WJ, Ahn SH. Results of free flap reconstruction after ablative surgery in the head and neck. Clin Exp Otorhinolaryngol 2015;8:167-73.

12. Tan BK, Por YC, Chen HC. Complications of the head and neck reconstruction and their treatment. Semin Plast Surg 2010;24:288-98.

13. Seo MH, Kim SM, Huan F, et al. Analysis of microvascular free flap failure focusing on the microscopic findings of the anastomosed vessels. J Craniofac Surg 2015;26:2047-51.

14. Ho MW, Brown JS, Magennis P, et al. Salvage outcomes of free tissue transfer in Liverpool: trends over 18 years (1992-2009). Br J Oral Maxillofac Surg 2012;50:13-8.

15. Hamoir M, Holvoet E, Ambroise J, et al. Salvage surgery in recurrent head and neck squamous cell carcinoma: Oncologic outcome and predictors of disease free survival. Oral Oncol 2017;67:1-9.

16. Wilkman T, Husso A, Lassus P. Clinical comparison of scapular, fibular, and iliac crest osseal free flaps in maxillofacial reconstructions. Scand J Surg 2018;1, 1457496918772365.

17. Wilkman T, Apajalahti S, Wilkman E, et al. A comparison of bone resorption over time: an analysis of the free scapular, iliac crest, and fibular microvascular flaps in mandibular reconstruction. J Oral Maxillofac Surg 2017;75:616-21.

18. Nao EE, Dassonville O, Chamorey E, et al. Head and neck free-flap reconstruction in the elderly. Eur Ann Otorhinolaryngol Head Neck Dis 2011;128:47-51. 
19. le Nobel GJ, Higgins KM, Enepekides DJ. Predictors of complications of free flap reconstruction in head and neck surgery: Analysis of 304 free flap reconstruction procedures. Laryngoscope 2012;122:1014-9.

20. Bhama PK, Patel SA, Khan U, et al. Head and neck free flap reconstruction in patients older than 80 years. $J$ Reconstr Microsurg 2014;30:523-30.

21. Goh CS, Kok YO, Yong CP, et al. Outcome predictors in elderly head and neck free flap reconstruction: A retrospective study and systematic review of the current evidence. J Plast Reconstr Aesthet Surg 2018;71:719-28.
22. Bianchi B, Ferri A, Ferrari S, et al. The free anterolateral thigh musculocutaneous flap for head and neck reconstruction: one surgeon's experience in 92 cases. Microsurgery 2012;32:87-95.

23. Smith GI, O'Brien CJ, Choy ET, et al. Clinical outcome and technical aspects of 263 radial forearm free flaps used in reconstruction of the oral cavity. Br J Oral Maxillofac Surg 2005;43:199-204. 